\title{
REVIEWS
} AgnieszKa MielcZareK ${ }^{1, C, E, F}$

\section{Photodynamic Therapy As a Promising Method Used in the Treatment of Oral Diseases}

${ }^{1}$ Department of Conservative Dentistry and Endodontics, Medical University of Warsaw, Poland

2 Institute of Optoelectronics, Military University of Technology, Warszawa, Poland

A - research concept and design; $\mathbf{B}$ - collection and/or assembly of data; $\mathbf{C}$ - data analysis and interpretation;

$\mathbf{D}$ - writing the article; $\mathbf{E}$ - critical revision of the article; $\mathbf{F}$ - final approval of article

\begin{abstract}
Photodynamic therapy (PDT) consists of three elements: photosensitizer, light and oxygen. The photosensitizer has the property of selective accumulation in abnormal or infected tissues without causing any damage to the healthy cells. This innovative therapeutic method has already been successfully adapted in many fields of medicine, e.g. dermatology, gynecology, urology and cancer therapy. Dentistry is also beginning to incorporate photodisinfection for treatment of the oral cavity. The antibacterial and fungicidal properties of the photosensitizer have been used to achieve better results in root canal treatment, periodontal therapy and the eradication of candidiasis in prosthodontics. The aim of this article is to discuss the effectiveness of photodynamic methods in the diagnosis and therapy of selected oral diseases. Scientific data and published papers regarding the antibacterial properties of PDT will be subjected to analysis. Photodynamic therapy will be discussed as an alternative treatment protocol in oncology, endodontics, periodontology and other fields of dentistry (Adv Clin Exp Med 2016, 25, 4, 799-807).
\end{abstract}

Key words: photodynamic therapy, PDT, photosensitizer, antibacterial therapy.

\section{Introduction}

The history of photodynamic therapy reaches back to the beginning of the twentieth century. Professor Herman von Tappeiner in 1904 used the phrase "photodynamic action" to describe interactions between specific chemical substances, oxygen and light. The term "photodynamic therapy" was later introduced by another German physician, Friedrich Meyer-Betz. The first experimental clinical studies tested the effectiveness of PDT in dermatology. The characteristic fluorescence of the photosensitizer in neoplastic lesions was used as photodynamic tumor detection [1]. Later on, photodynamic diagnosis and therapy was adapted in the areas of gynecology and urology. PDT has a specific mechanism of selective accumulation in target tissues. The cytostatic effects depend on the photosensitizing properties of the dye and its ability of retention in tumor tissues or pathological cells [2]. The aim of this paper is to present and discuss the effectiveness of photodynamic therapy in a specific area, the oral cavity.

\section{Basics of Photodynamic Therapy}

Photodynamic therapy is a new treatment protocol used in the management of various diseases. Classic PDT is a sequence of specific steps [3]:

- systematic or topical administration of a photosensitizer (PS) to the patient,

- selective retention of the PS in the target tissues,

- irradiation with light,

- the photochemical reaction and selective destruction of damaged tissues.

The photosensitizer is a principal component of PDT. This chemical substance or its inactive precursor may be administered locally or systemically. It is sensitive to light of a specific wave- 

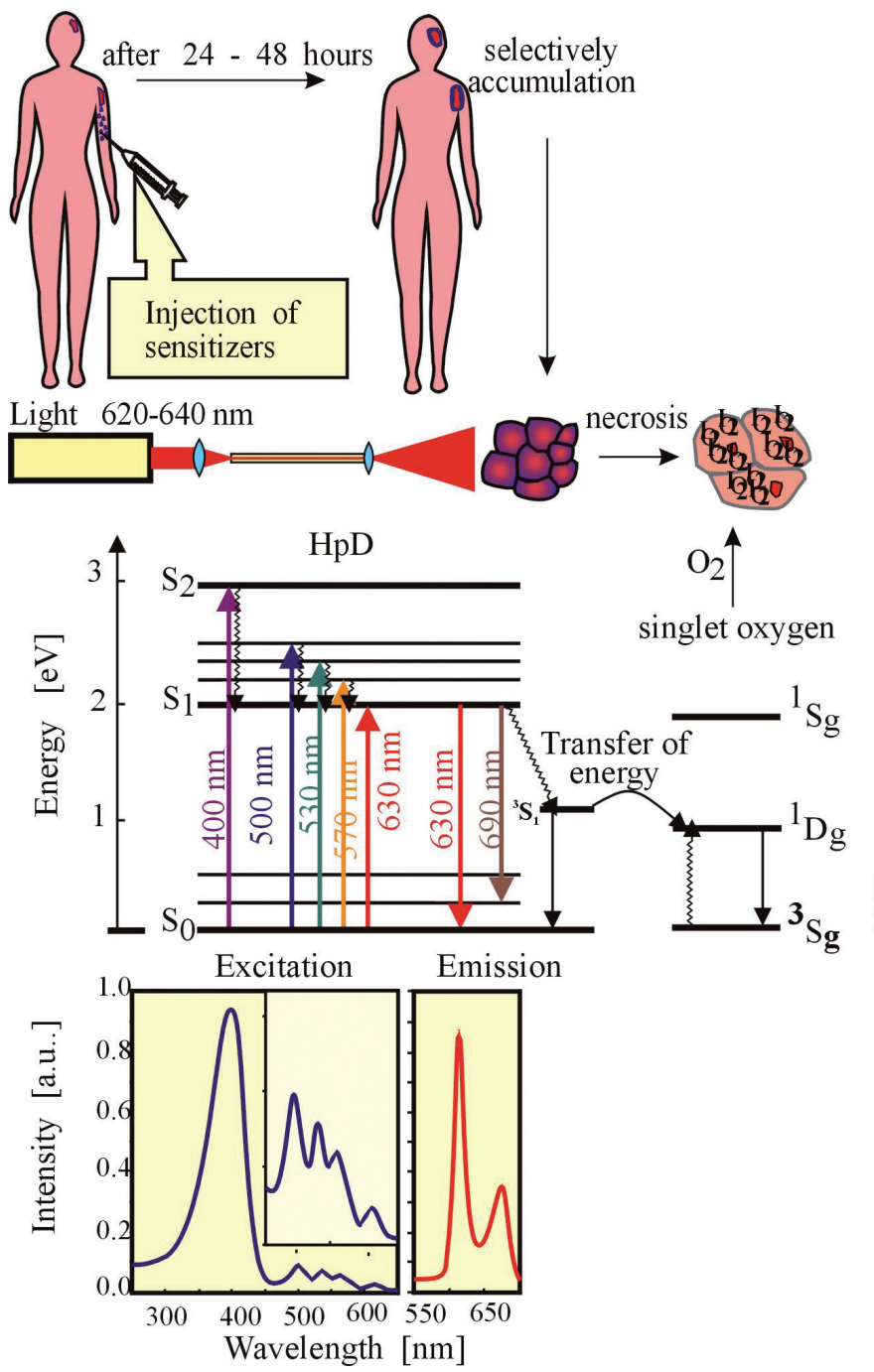

Fig. 1. Selective absorption, fluorescence of PS and mechanism of generation of singlet oxygen

length. There are two types of reaction during PDT [4]. Irradiation with light results in a transition of the photosensitizer from a low-energy ground state to an excited singlet state. The excited singlet state may then decay back with an emission of fluorescence or may undergo a change to a triplet state (Fig. 1). This excited triplet state can undergo two kinds of reactions. In a type I reaction, the activated photosensitizer reacts directly with a substrate molecule, such as a cell membrane. An electron or hydrogen is removed from the molecule to form free radicals. Subsequently the radicals react with oxygen and produce highly reactive oxygen species: superoxide, hydroxyl radicals and singlet oxygen [5]. In a type II reaction, the excited PS interacts directly with oxygen to form oxygenated products. These two reaction mechanisms are strictly dependent on oxygen tension and photosensitizer concentration [6].

There are different sources of light used in PDT. A noncoherent light source, like a conven- tional arc lamp, was commonly used in the past. Nowadays, because of its many drawbacks (low light intensity, significant increase in temperature in the irradiated tissues) it has been replaced by other devices [7]. Tungsten filament, metal halide and fluorescent lamps can also be listed among the non-laser light applicators, especially for large areas [8]. The other significant group of devices used in PDT is lasers: Dye lasers pumped by argon, metal vapor lasers, Nd:YAG and, most recently, diode lasers $[7,8]$. Diode lasers are small, portable and inexpensive, which makes them more commonly used in PDT therapy. Light emitting diodes have similar advantages (lightweight, flexible and less expensive) and are also successfully applied during photodynamic treatment [9].

There is a large number of photosensitizers applied in PDT therapy. They are divided into major groups which differ in chemical structure and origin: Phenothiazine dyes (methylene blue, toluidine blue); phthalocyanine dyes (aluminum disulphonated phthalocyanine, cationic zinc phthalocyanine, naphthalocyanine); porphyrins (Photofrin ${ }^{\circledR}$, ALA (5-aminolevulinic acid) - precursor of actual photosensitizer protoporphyrin IX), chlorins (temoporfin $\left(\right.$ Foscan $\left.^{\circledR}\right)$ ), chlorin $\mathrm{e}_{6}$; xanthenes (erythrosine), monoterpenes (azulene) $[10,11]$ (Fig. 2). The first photosensitizers, including porphyrins, were discovered about 40 years ago and are called first generation photosensitizers. The second generation was more effective in generating singlet oxygen and refers to porphyrin derivatives and synthetics. In the third generation, photosensitizers became modified by the incorporation of a photo bleaching capability, antibody conjugates or protein/receptor system [12, 13]. This helps to increase the selectivity of a photosensitizer to tumor tissues. Conjugating an antibody to photosensitizers reduces healthy cell location and increases affinity to tumor cells [14]. Furthermore, photosensitizers binded to a single-chain monoclonal antibody ( $\mathrm{scFv}$ ) fragment are more effectively cleared from the circulation, which decreases their toxic effect to healthy tissues [14]. Another approach is the use of a molecular carrier such as a liposome nanospecies. This type of modified photosensitizers with poor solubility in aqueous media are prevented from delivery into the bloodstream, which helps to keep the concentration in the targeted tissues at a high level $[15,16]$. Most of these substances become active under the influence of red light between $630-700 \mathrm{~nm}$ that penetrates the tissues at a depth of $0.5 \mathrm{~cm}(630 \mathrm{~nm})$ to $1.5 \mathrm{~cm}($ at $700 \mathrm{~nm})$ [17].

The last decades of intensive research have confirmed the effectiveness of photodynamic therapy in the management of various systemic dis- 

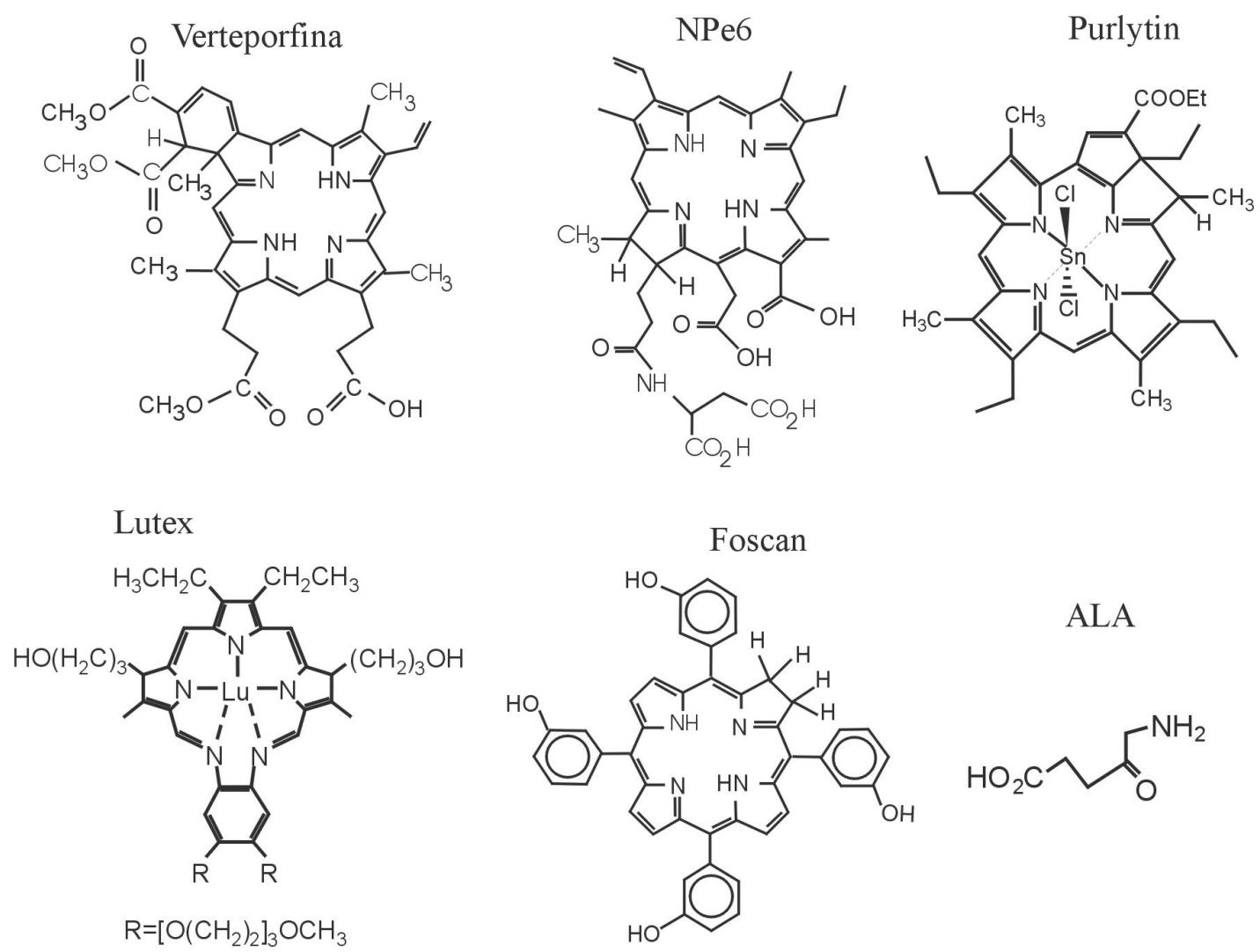

Fig. 2. Chemical structures of photosensitizers

eases and localized infections. PDT has been approved for the treatment of cancer [18], bacterial [19], fungal [20], viral [21] and parasitic infections [22]. However, most of the photosensitizers used in PDT are significantly more effective in inactivating Gram-positive bacteria than fungi and Gram-negative bacteria [23]. The fungal cell and outer membrane of Gram-negative bacteria very often restrict binding and prevent the penetration of photosensitizers. To increase affinity to the target cells, photosensitizers required modification. The chemical structure was modified by imparting a positive charge, combining it with permeabilizing agents (polymyxin nanopeptide, EDTA) and creating nanoparticles for the delivery and release system $[23,24]$.

\section{Cancer Therapy}

Squamous cell carcinoma (SCC) is the most frequent malignant transformation localized in the oral cavity [25]. The current treatment standards include surgery, chemotherapy and radiotherapy. But all of these methods may cause serious side effects, often permanent, that hinder normal functioning of the body [26]. Extensive radiotherapy may cause mucositis, xerostomia, loss of taste and smell and even osteoradionecrosis. Surgi- cal excision may leave patients with aesthetic and functional disabilities, impairing swallowing and speaking [27].

Photodynamic therapy is a relatively new and promising method of treatment for oral cancer. Reactions based on the production of cytotoxic oxygen induce apoptosis, destruction of vital organelles and vascular shutdown leading to hypoxia and cell death. A very important aspect of this process is survival of the surrounding normal tissues. Additionally, rapid migration of cells and healing must stay undisturbed, no ulceration or fibrosis should appear [28].

Three substances have been approved by different countries to be used in the treatment of cancer localized in the oral cavity: Photofrin ${ }^{\circledR}$, Foscan ${ }^{\circledR}$ and 5-Aminolevulinic acid 9 (ALA). Photofrin and ALA have worldwide acceptance, Foscan hasn't been approved in the USA [29]. Photofrin is administered intravenously at a dose of $2 \mathrm{mg} / \mathrm{kg}$. After $48 \mathrm{~h}$, required for accumulation of the drug in cancer cells, the tumor is illuminated at $630 \mathrm{~nm}$ [5]. The major treatment indication for Photofrin is therapy of large solid tumors at different stages. Biel, in his 15-year-long observations, confirmed the effectiveness of PDT in the therapy of early-stage primary and recurrent carcinomas of the oral cavity (palate and floor of the mouth) and recurrent infiltrating carcinomas as an addi- 
tional intra-operative treatment [30]. The positive response of maxillary gingival squamous cell carcinoma to Photofrin ${ }^{\circledR}$ was also proved by Mang, who had no recurrence after 25 months following irradiation of the tissues [31].

Foscan is a second-generation photosensitizer. It is assigned for the palliative treatment of advanced head and neck cancers that did not respond to primary therapy [5]. It is usually injected at a dose of $0.15 \mathrm{mg} / \mathrm{kg}$ and activated with light at $652 \mathrm{~nm}$ after 4 days of delay [26]. The treatment protocol based on the use of this photosensitizer is directed to patients who cannot be subjected to surgery, chemotherapy or radiotherapy. Foscan gives them a chance for remission, reduction of cancer-related complications and organ dysfunctions [32].

5-Aminolevulinic acid (ALA) is a prodrug and a biological precursor of the photosensitizer protoporphyrin IX (PpIX) in the heme biosynthesis pathway [33]. ALA restrains the first stage of porphyrin synthesis, causing accumulation of the actual photosensitizer, PpIX [34]. ALA is limited to superficial lesions. It is applied topically and, like most photosensitizers given locally, does not have the ability to penetrate deep in the tissues. Intralesional injections often cause significant pain to the patient and systemic administration may cause side-effects [35], such as headache, nausea, fatigue and paraesthesia $[36,37]$. Repeated systemic application of ALA may also cause damage to hepatocytes and impairment of hepatic functions [38]. In the oral cavity, PDT with the use of ALA results in superficial necrosis and little scarring without significant toxicity [39]. These properties appear to be useful in the treatment of oral leukoplakia, erythroleukoplakia and oral verrucous hyperplasia, premalignant lesions with the potential to convert to squamous cell carcinoma and verrucous carcinoma [5]. Chen, in his publication, described complete regression in all cases of oral verrucous hyperplasia after multiple sessions with ALA topical application [33]. Erythroleukoplakia was completely reduced in $75 \%$ of cases and oral leukoplakia only in $34 \%$, when lesions were irradiated twice a week. Better results were reported by Seron [40]. A complete response was obtained in 10 out of 12 patients with oral leukoplakia. The effectiveness of ALA in the therapy of leukoplakia was also monitored by Kübler [41]. In the group of 12 patients, 5 showed complete response to the treatment protocol, four demonstrated partial recovery, and in 3 cases there were no results. There are differences in ALA application procedures between the authors cited above, but all results confirmed the effectiveness of PDT in the management of premalignant lesions. Therapeutic results may be improved by the modification of the photosensitizer's molecule. It has been confirmed that aminolevulinic acid (ALA) and its methyl ester (Metvix) encapsulated in liposomes improve the quality and optimize the results of PDT $[42,43]$. Using a metalloproteinase inhibitor may be an enhancing factor of PDT cancer therapy. Further clinical studies are required to determine the most effective protocol of treatment.

\section{Application of PDT in Periodontal Therapy}

The main objective of periodontal therapy is the elimination of an inflammatory reaction affecting the tissues surrounding a tooth [44]. The pathogens responsible for this pathological process are present in dental plaque and niches in the oral cavity. The reduction or elimination of these etiological factors is the main purpose of initial periodontal treatment. Scaling, root planing and the introduction of proper oral habits are essential for the success of the hygienic or pre-surgical phase of this therapy [45]. Systemic administration of antibiotics has also been advocated in the treatment protocols, however this does not give significant improvement over mechanical debridement and may lead to the development of antibiotic resistance [46].

PDT is a promising new approach to periodontal nonsurgical therapy. Many studies have been conducted to confirm the effectiveness of this treatment modality. Experimental animal models were created to analyze inflammatory conditions in gingival tissues after the administration of PDT. Periodontitis induced in rats demonstrated a good response to PDT. There was a reduced expression of inflammatory cytokines, lower levels of TNF-ALFA in the gingival tissues and decreased neutrophil migration [47-49]. All these factors manifested in a significant reduction of bone resorption. Inhibition of bone loss is an essential indicator of successful periodontal therapy [50]. In other observations of PDT application, there was a remarkable reduction of lymphocytes in the irradiated tissues [51]. An inactivation of host destructive cytokines, which prevent periodontal tissue regeneration, is also an important outcome of this therapy [52]. In terms of antibacterial properties, it has been confirmed that topically applied toluidine blue and laser light are able to kill P.gingivalis from the gingival crevice without any damage of the adjacent tissues. Even $100 \%$ of P.gingivalis may be eliminated with the appropriate concentration of photosensitizer and red light intensity [53].

Randomized, controlled clinical trials are a source of other, different conclusions regarding 
the efficacy of PDT in the reduction of periodontitis. Some studies have been conducted to compare the therapeutic results achieved after scaling and root planing (SRP) alone, and scaling and root planing (SRP) followed by photodisinfection (PDT). Three basic clinical measurements were evaluated: Pocket probing depth (PPD), clinical attachment level (CAL) and bleeding on probing (BOP). Andersen et al. [46] observed significant improvements of the investigated parameters after a combined single application of SRP and PDT. Slightly different results were described by Lulic et al. [54]. Repeated (5 times) application of PDT adjunctive to debridement improved clinical outcomes in residual pockets. The differences were noted only 6 months after the initial treatment. After 12 months from the beginning of the clinical trial, there were no differences between the two groups. Observations described by Chondros and Christodoulides et al. confirmed a significantly higher reduction of bleeding scores only, after a single application of combined PDT and SRP $[48,55]$. De Oliveira carried out a study in a group of patients with aggressive periodontitis. Mechanical debridement with or without photodisinfection didn't show any differences in the clinical results between the two treatment protocols [49].

All the cited randomized, controlled clinical trials are very divergent in their final conclusions. Many of the parameters accepted for each of the studies are different, so it is difficult to compare the results. Photodisinfection has many essential advantages: Reduction of the treatment time, no need for anesthesia, eradication of bacteria in a very short time, unlikely development of resistance by the targeted pathogens [49]. However, PDT cannot be applied as a monotherapy for the treatment of patients with periodontal problems. Further studies with larger sample sizes and longer time of observation are required to confirm the efficacy of SRP and PDT in combined, non-surgical periodontal therapy.

\section{Photo-activated Disinfection in Endodontics}

The main purpose of endodontic treatment is to disinfect the root canal system and eradicate bacteria that cause the infection [56]. Conventional endodontic treatment consists of mechanical debridement and chemical irrigation with a sequence of many different substances. However complete the debridement, removal of residing bacteria, effective irrigation and evacuation of infected tissues is practically impossible, because of the anatomical complexity of the root canal system [57]. Nega- tive cultures in the canals at the time of obturation are correlated with a high, $94 \%$ success rate of the therapy, whereas positive cultures decrease the rate to $68 \%$ [58]. Efficient disinfection is undoubtedly difficult to achieve but essential for the success of the chemomechanical endodontic debridement.

Photodynamic therapy has recently been studied as a new alternative regimen for the root canal treatment. Many studies have been performed to assess the potential of PDT to eliminate polymicrobial endodontic infection. The microorganisms usually responsible for a build-up of biofilm within the root canals are: Fusobacterium nucleatum, Prevotella intermedia, Streptococcus intermedius and Peptostreptococcus micros. PDT with a combination of standard chemomechanical methods showed very promising results in the reduction of these pathogens [59-63]. The additional application of a photosensitizer and light significantly lowered the number of bacteria remaining in the canals in comparison to conventional treatment alone. The results were improved by $7.5 \%$ [59], 10\% [61] and 15\% [62] when chemomechanical debridement was followed by PDT. The overall reduction achieved by the researchers reached the level of $99.9 \%$ after two repeated combined therapies [59] and $86.5 \%$ after a single application [60].

The results of the studies regarding PDT efficacy in the eradication of Enteroccocus faecalis are less consistent. E. faecalis is considered to be a type of bacteria associated with root canals that have developed recurrent infections [64]. E. faecalis has a very specific ability to form an impenetrable biofilm, resistant to commonly used intracanal medications [65]. A significant number of the published articles confirmed the potential of PDT to be an adjunctive antibacterial procedure against this species [66]. In some publications, the bacterial survival rate reached very low, $0.1 \%$ or $0.8 \%$ of the pretreatment concentration in the root canal system $[67,68]$. There are also some reports which did not agree with PDT having any additional effect on mechanical preparation and chemical irrigation [69]. Conventional debridement reduced the population of bacteria without any additional effects of PDT. All the published observations were based on different experimental conditions. The concentration and type of photosensitizer, time of light exposure, and energy of the laser may affect the PDT. The results are mostly very promising. However, the root canal system has a complicated architecture with an irregular diagonal of the canal, lateral canals and deltas located in the area of the apex. These conditions may interrupt penetration of the photosensitizer or light which is normally distributed with the use of a fiberglass applicator. Further studies are required to establish 
the exact correlation between the photosensitizer, light and bacteria responsible for the inflammation within the root canals.

\section{Fungicidal Efficacy of Photodisinfection}

Denture stomatitis is an infection of the oral mucosa localized in the area covered by a removable denture, usually the palate [70]. The etiology is multifactorial, however Candida albicans is thought to be the most virulent species causing the inflammation. Newton classified denture stomatitis in three types: I - localized simple inflammation, II - generalized simple inflammation, III - inflammatory papillary hyperplasia [71]. Treatment is based on good oral hygiene, local or systemic administration of antifungal medications, and replacement of the old dentures colonized by the pathogens.

Various protocols of photodynamic therapy have been tested against Candida albicans. Most of them have been conducted under in vitro conditions. There were also a small number of animal in vivo trials that delivered significant data relating to the fungicidal efficacy of PDT [72-74]. Oral candidiasis in rat and murine models appeared to be susceptible to photodisinfection. High concentrations of the photosensitizer (methylene blue) completely eliminated $C$. albicans from the infected oral mucosa [72]. The viability of the pathogen was significantly reduced without any damaging effects to the irradiated area. Histological alterations in the animal tissues were not observed. Photodynamic chemotherapy increases membrane permeability in C. albicans and promotes cell death [75].

The effectiveness of PDT in the therapy of denture stomatitis in the human body has not been properly investigated so far. Mima et al. described the treatment results of five cases infected with C. albicans [76]. Four patients showed a resolution of candidiasis after photodisinfection. A recurrence was observed in three patients after 30 days during the follow-up studies; however, denture stomatitis represents a high frequency of recurrence after conventional treatment with antifungal medications. PDT also displayed a short-term therapeutic effect.

The same author also conducted a clinical trial to compare the effects of photodisinfection with a topical application of nystatin, which is conventionally used in the treatment of denture stomatitis [77]. PDT appeared to be as effective as the topi- cal antibiotic in reducing the number of pathogens from dentures and palates. A high rate of recurrence was observed in both groups. A smaller number of sessions is required to achieve the same clinical results as after multiple application of nystatin.

Photodynamic therapy has a great potential to become a new standard protocol for the treatment of oral candidiasis. There is a great need to find an effective and noninvasive fungicidal therapy for immunodeficient patients and elderly people. PDT meets these criteria. The application procedure is easy to perform in the oral cavity. It is not painful and no adverse tissue reactions have been recorded so far.

\section{Conclusions}

Photodynamic therapy is currently used in many fields of medicine. It has been successfully introduced in dermatology, urology and gynecology. It has become accepted as an additional treatment protocol for cancer therapy and many skin diseases. The selectivity of PDT was also adapted for diagnosis and treatment in the area of the oral cavity. Photodynamic therapy has many indisputable advantages. It is safe for human tissues and selectively eliminates cells that are affected by pathogens. The photosensitizer is able to penetrate dead or damaged tissues without developing a resistance that might appear after long-term antibiotic therapy. PDT has a broad therapeutic window and is effective in the eradication of organisms, organized either in colonies or biofilm.

Photodynamic therapy is a promising modality for the treatment of oral diseases. It can intensify the results of conventional endodontic root canal disinfection and periodontal debridement. Fungicidal photodisinfection displays a comparable effectiveness to medications routinely used in the therapy of candidiasis, with a similar rate of recurrence. Further clinical studies are required to determine the most efficient and safe parameters of PTD, but so far the clinical results are very promising. Some photosensitizers have already been approved for the application of cancer therapy in the human body. They give a chance for remission, reduce tumor-related organ dysfunctions and increase the standard of life for terminally ill patients. The application of light also has diagnostic properties. In the oral cavity, it helps to locate caries, dental plaque, staining or calculus. Early detection and diagnosis in these cases prevents the progression of demineralization and helps to maintain healthy dentition. 


\section{References}

[1] Dougherty TJ, Gomer CJ, Henderson BW, Jori G, Kessel D, Korbelik D, Moan J, Peng Q: Review photodynamic therapy. J Natl Cancer Inst 1998, 90, 889-905.

[2] Kwasny M: Light sources and diagnostic systems currently used in photodynamic therapy. Optica Applicata 2002, 32, 673-684.

[3] Nowis D, Makowski M, Stoklosa T, Legat M, Issat T, Gołąb T: Direct tumor damage mechanisms of photodynamic therapy. Acta Biochim Pol 2005, 52, 339-352.

[4] Dolmans EJGJD, Fukumura D, Jain KR: Photodynamic therapy for cancer. Nat Rev Cancer 2003, 3, 380-387.

[5] Konopka K, Goslinski T: Photodynamic therapy in dentistry. J Dent Res 2007, 86, 694-707.

[6] Tromberg BJ, Orenstein A, Kimel S, Barker SJ, Hyatt J, Nelson JS, Berns MW: In vivo tumor oxygen tension measurements for the evaluation of the efficiency of photodynamic therapy. Photochem Photobiol 1990, 52, 75-85.

[7] Huang Z: A review of progress in clinical photodynamic therapy. Technol Cancer Res Treat 2005, 4, $283-293$.

[8] Brancaleon L, Moseley H: Laser and non-laser light sources for photodynamic therapy. Lasers Med Sci 2002, 17, 2002, 173-186.

[9] Peloi LS, Soares RSS, Biondo CEG, Souza VR, Hioka N, Kimura E: Photodynamic effect of light-emitting diode light on cell growth inhibition induced by methylene blue. J Biosci 2008, 33, 231-237.

[10] Goslinski T, Konopka K, Piskorz J, Kryjewski M, Wierzchowski M, Sobiak S: Prospects for photodynamic antimicrobial chemotherapy - PACT. Post Microbiol 2008, 47, 447-456.

[11] Dave D, Desai U, Despande N: Photodynamic therapy: A view thought light, J Orofac Res 2012, 2, 82-86.

[12] Allison RR, Downie GH, Cuenca R, Xin-Hua Hu, Childs CJH, Sibata CH: Photosensitizers in clinical PDT. Photodiag Photodyn Ther 2004, 1, 27-42.

[13] Moser JG: Definitions and general properties of $2^{\text {nd }} \& 3^{\text {rd }}$ generation photosensitizers. Harwood Academic Publishers, Amsterdam 1998, 3-8.

[14] Staneloudi C, Smith KA, Hudson R, Malatesti N, Savoie H, Boyle RW: Development and characterization of novel photosensitiser: scFv conjugates for use in photodynamic therapy of cancer. Immunology 2007, 120, 512-517.

[15] Konan YN, Gurny R, Alléman E: State of the art in the delivery of photosensitisers for photodynamic therapy. J Photochem Photobiol B 2002, 66, 89-106.

[16] Josefsen LB, Boyle RW: Photodynamic therapy: Novel third-generation photosensitizers one step closer? Br J Pharmacol 2008, 1, 1-3.

[17] Salva KA: Photodynamic therapy: Unapproved uses, dosages, or indications. Clin Dermatol 2002, 20, 571-581.

[18] Allison RR, Bagno VC, Cuenca R, Downie GH, Sibata CH: The future of photodynamic therapy in oncology. Future Oncol 2006, 2, 53-71.

[19] Usacheva MN, Teichert MC, Biel MA: Comparison of the methylene blue and toluidine blue photobactericidal efficacy against gram- positive and gram- negative microorganism. Lasers Surg Med 2001, 29, 165-173.

[20] Donelly RF, McCarron PA, Tunney MM: Antifungal photodynamic therapy. Microbiol Res 2008, 163, 1-12.

[21] Mohr H, Lambrecht B, Selz A: Photodynamic virus inactivation of blood components. Immunol Invest 1995, 24, 73-85.

[22] Kassab K, Amor BT, Jori G, Coppellotti O: Photosensitization of Colpoda inflate cysts by meso-substituted catonic porphyrins. Photochem Photobiol Sci 2002, 1, 560-564.

[23] Kharkwal GB, Sharma SK, Ying-Ying H, Dai T, Hamblin MR: Photodynamic therapy for infections: Clinical applications. Lasers Surg Med 2011, 43, 755-767.

[24] Pagonis TC, Chen J, Fontana CR, Devalapally H, Ruggiero K, Song X, Foschi F, Dunham J, Skobe Z, Yamazaki H, Kent R, Tanner ACR, Amiji MM, Soukos NS: Nanopartice-based endodontic antimicrobial photodynamic therapy. J Endod 2010, 36, 322.

[25] Massano J, Ragateiro FS, Januario G, Ferreira A: Oral squamous cell carcinoma: review of prognostic and predictive factors. Oral Surg Oral Med Oral Pathol Oral Radiol Endod 2006, 102, 67-76.

[26] Dilkes MG, Benjamin E, Ovaisi S, Banerjee AS: Treatment of primary mucosal head and neck squamous cell carcinoma using photodynamic therapy: Results after 25 treated cases. J Laryngol Otol 2003, 117, 713-717.

[27] Dilkes MG, DeJode ML, Gardiner Q, Kenyon GS, McKelvie P: Treatment of head and neck cancer with photodynamic therapy: Results after one year. J Laryngol Otol 1995, 109, 10721076.

[28] Dilkes MG, DeJode ML, Rowntree-Taylor A, McGilligan JA, Kenyon GS, McKelvie P: m-THPC Photodynamic therapy for head and neck cancer. Lasers Med Sci 1996, 11, 23-29.

[29] Agostinis P, Berg K, Cengel KA, Foster TH, Girotti AW, Gollnick SO, Hahn SM, Hamblin MR, Juzeniene A, Kessel D, Korbelik M, Moan J, Mroz P, Nowis D, Piette J, Wilson BC, Golab J: Photodynamic therapy of cancer: An update. CA Cancer J Clin 2011, 61, 250-281.

[30] Biel M: Advances in photodynamic therapy for the treatment of head and neck cancers. Lasers Surg Med 2006, 38, 349-355.

[31] Mang TS, Sullivan M, Cooper M, Loree T, Rigual N: The use of photodynamic therapy using $630 \mathrm{~nm}$ laser light and porfimer sodium for the treatment of oral squamous cell carcinoma. Photodiagnosis Photodyn Ther 2006, 3, 272-275.

[32] Hopper C, Niziol C, Sidhu M: The cost-effectiveness of Foscan mediated photodynamic therapy (Foscan-PDT) compared with palliative chemotherapy, extensive palliative surgery or 'no treatment' for patients with advanced head and neck cancer in the UK. Oral Oncol 2004, 40, 372-382. 
[33] Chen HM, Chen Ch, Yang H, Yen-Ping Kuo M, Kuo YS, Lan WH, Wang YP, Tsai T, Chiang CP: Successful treatment of oral verrucous hyperplasia with topical 5-aminolevulinic acid-mediated photodynamic therapy. Oral Oncol 2004, 40, 630-637.

[34] Dabrowski Z, Kwasny M, Kaminski J, Beldowicz M, Lewicka L, Obukowicz B, Kaliszewski M, Pirozynska E: The syntesis and application of 5- aminolevulinic acid (ALA) derivatives in photodynamic therapy and photodiagnosis. Acta Pol Pharm 2003, 60, 219-224.

[35] Donnelly RF, McCarron PA, Woolfson AD: Derivatives of 5-Aminolevulinic acid for photodynamic therapy. Perspect Medicin Chem 2007, 1, 49-63.

[36] Wachowska M, Muchowicz A, Firczuk M, Gabrysiak M, Winiarska M, Wańczyk M, Bojarczuk K, Golab J: Aminolevulinic Acid (ALA) as a prodrug in photodynamic therapy of cancer. Molecules 2011, 16, 4140-4164.

[37] Ackroyd R, Brown N, Vernon D, Roberts D, Stephenson T, Marcus S, Stoddard C, Reed M: 5-Aminolevulinic acid photosensitization of dysplastic Barrett's esophagus: A pharmacokinetic study. J Photochem Photobiol 1999, 4, 656-662.

[38] Weiss TS, Pahernik S, Scheruebl I, Jauch KW, Thasler WE: Cellular damage to human hepatocytes through repeated application of 5-aminolevulinic acid. J Hepatol 2003, 4, 476-482.

[39] Kübler AC: Photodynamic therapy, Medical Laser Application 2005, 20, 37-45.

[40] Sieron A, Adamek M, Kawczyk-Krupka A, Mazur S, Ilewicz L: Photodynamic therapy (PDT) using topically applied $\delta$-aminolevulinic acid (ALA) for the treatment of oral leukoplakia. J Oral Pathol Med 2003, 32, 330-336.

[41] Kübler AC, Haase T, Rheinwald M, Barth T, Muhling J: Treatment of oral leukoplakia by topical application of 5-aminolevulinic acid. Int J Oral Maxillofac Surg 1998, 27, 466-469.

[42] Jurczyszyn K, Czapińska E, Gamian E, Hotowy K, Terlecki G, Symonowicz K, Osiecka B, Bronowicz A, Ziółkowski P: Matrix metalloproteinase-3 induction following photodynamic therapy with liposomal formulations of aminolevulinic acid and its methyl ester. Acta Bio-Optica Inform Med Eng 2010, 16, 182-186.

[43] Osiecka B, Jurczyszyn K, Symonowicz K, Bronowicz A, Ostasiewicz P, Czapińska E, Hotowy K, Krzystek-Korpacka M, Gebarowska E, Izykowska I, Dziegiel P, Terlecki G, Ziółkowski P: In vitro and in vivo matrix metalloproteinase expression after photodynamic therapy with a liposomal formulation of aminolevulinic acid and its methyl ester. Cell Mol Biol Lett 2010, 15, 630-650.

[44] Drisco CH: Non-surgical periodontal therapy. Periodontology 2000, 25, 77-88.

[45] Morrison EC, Ramfjord SP, Hill RW: Short-therm effects of initial nonsurgical periodontal treatment (hygienic phase). J Clin Periodontol 2007, 7, 199-211.

[46] Andersen R, Loebel N, Hammond D: Treatment of periodontal disease by photodisinfection compared to scaling and root planing. J Clin Dent 2007, 18, 34-38.

[47] Carvalho AS, Napimoga MH, Coelho-Campos J, Silva-Filho VJ, Thedei G: Photodynamic therapy reduces bone resorption and decreases inflammatory response in an experimental rat periodontal model. Photomed Laser Surg 2011, 29, 735-740.

[48] Christodoulides N, Nikolidakis D, Chondros P, Becker J, Schwarz F, Rössler R, Sculean A: Photodynamic therapy as adjunct to non-surgical periodontal treatment: A randomized controlled clinical trial. J Periodontol 2008, $79,1638-1644$.

[49] de Oliveira RR, Schwartz-Filho HO, Novaes AB Jr, Taba M Jr: Antimicrobial Photodynamic therapy in the nonsurgical treatment of aggressive periodontitis: A preliminary randomized controlled clinical study. J Periodontol 2007, 78, 965-973.

[50] Kömerik N, Nakanishi H, MacRobert AJ, Henderson B, Speight P, Wilson M: In vivo killing of porphyromonas gingivalis by toluidine blue-mediated photosensitization in an animal model. Antimicrob Agents Chemother 2003, 47, 932-940.

[51] Qin YL, Luan XL, Bi LJ, Sheng YQ, Zhou CN, Zhang ZG: Comparison of toluidine blue-mediated photodynamic therapy and conventional scaling treatment for periodontitis in rats. J Periodont Res 2008, 2, 162-167.

[52] Braham P, Herron C, Street C, Darveau R: Antimicrobial photodynamic therapy may promote periodontal healing through multiple mechanisms. J Periodontol 2009, 11, 1790-1798.

[53] Bhatti M, Macrobert A, Meghji S, Henderson B, Wilson M: Effect of dosimetric and physiological factors on the lethal photosensitization of Porphyromonas gingivalis in vitro. Photochem Photobiol 1997, 65, 1026-1031.

[54] Lulic M, Leiggener GI, Salvi GE, Ramseier CA, Mattheos N, Lang NP: One-year outcomes of repeated adjunctive photodynamic therapy during periodontal maintenance: a proof-of-principle randomized controlled clinical trial. J Clin Periodontol 2009, 36, 661-666.

[55] Chondros P, Nikolidakis D, Christodoulides N, Rössler R, Gutknecht N, Sculean A: Photodynamic therapy as adjunct to non-surgical periodontal treatment in patients on periodontal maintenance: A randomized controlled clinical trial. Lasers Med Sci 2009, 24, 681-688.

[56] Fimple JL, Fontana CR, Foschi F, Ruggiero K, Song X, Pagonis TC, Tanner ACR, Kent R, Doukas AG, Stashenko PP, Soukos NS: Photodynamic treatment of endodontic polymicrobial infection in vitro. J Endod 2008, $34,728-734$.

[57] Siqueira JF Jr, Rôças IN, Paiva SS, Magalhães KM, Guimarães-Pinto T: Cultivable bacteria in infected root canals as identified by 16 S rRNA gene sequencing. Oral Microbiol Immunol 2007, 22, 266-271.

[58] Sjorgen U, Figdor D, Persson S, Sundqvist G: Influence of infection at the time of root filling on the outcome of endodontic treatment of teeth with apical periodontitis. Int Endodontic J 1997, 30, 297-306.

[59] Garcez AS, Nunez SC, Hamblin MR, Ribeiro MS: Antimicrobial effect of photodynamic therapy on patients with necrotic pulps and periapical lesions. J Endod 2008, 34, 138-142. 
[60] Raymond N, Singh F, Papamanou DA, Xiaoqing S, Patel C, Holewa C, Patel N, Klepac-Ceraj V, Fontana CR, Kent R, Pagonis TC, Stashenko PP, Soukos NS: Endodontic photodynamic therapy ex vivo. J Endod 2011, 37, 217-222.

[61] Bonsor SJ, Nichol R, Reid TMS, Pearson GJ: Microbal evaluation of photo-activated disinfection in endodontics (an in vivo study). Br Dent J 2006, 200, 337-341.

[62] Bonsor SJ, Nichol R, Reid TMS, Pearson GJ: An alternative regimen for root canal disinfection. Br Dent J 2006, 201, 101-105.

[63] Pinheiro SL, Schenka AA, Neto AA, de Souza CP, Rodriquez HM, Ribeiro MC: Photodynamic therapy in endodontic treatment of deciduous teeth. Lasers Med Sci 2009, 24, 521-525.

[64] Lee MT, Bird PS, Walsh LJ: Photo-activated disinfection of root canals: A new role for lasers in endodontics. Aust Endod J 2004, 30, 93-98.

[65] Distel JW, Hatton JF, Gillespie MJ, Biofilm formation in medicated root canals. J Endod 2002, 28, 689-693.

[66] Siddiqui SH, Awan KH, Javed F: Bactericidal efficacy of photodynamic therapy against Enterococcus faecalis in infected root canals: A systematic literature review. Photodiagnosis Photodyn Ther 2013, 10, 632-643.

[67] Rios A, He J, Glickman GN, Spears R, Schneiderman ED, Honeyman AL: Evaluation of photodynamic therapy using a light-emitting diode lamp against Enterococcus faecalis in extracted human teeth. J Endod 2011, 37, 856-859.

[68] Garcez AS, Núñez SC, Lage-Marques JL, Jorge AOC, Ribeiro MS: Efficiency of NaOCl and laser-assisted photosensitization on the reduction of Enterococcus faecalis in vitro. Oral Surg Oral Med Oral Pathol Oral Radiol Endod 2006, 102, 93-98.

[69] Souza LC, Brito PR, de Oliveira JC, Alves FR, Moreira EJ, Sampaio-Filho HR, Rôças IN, Siqueira JF Jr: Photodynamic therapy with two different photosensitizers as a supplement to instrumentation/irrigation procedures in promoting intracanal reduction of Enterococcus faecalis. J Endod 2010, 36, 292-296.

[70] Arendorf TM, Walker DM: Denture stomatitis: A review. J Oral Rehabil 1987, 14, 217-227.

[71] Newton AV: Denture sore mouth. A possible etiology. Br Dent J 1962, 112, 357-360.

[72] Teichert MC, Jones JW, Usacheva MN, Biel MA: Treatment of oral candidiasis with methylene blue-mediated photodynamic therapy in an immunodeficient murine model. Oral Surg Oral Med Oral Pathol Oral Radiol Endod 2002, 93, 155-160.

[73] de Oliveira Mima EG, Pavarina AC, Dovigo LN, Vergani CE, de Souza Costa CA, Kurachi C, Bagnato VS: Susceptibility of Candida albicans to photodynamic therapy in a murine model of oral candidosis. Oral Surg Oral Med Oral Pathol Oral Radiol Endod 2010, 109, 392-401.

[74] da Silva Martins J, Junqueira JC, Faria RL, Santiago NF, Rossoni RD, Colombo CED, Jorge AOC: Antimicrobial photodynamic therapy in rat experimental candidiasis: Evaluation of pathogenicity factors of Candida albicans. Oral Surg Oral Med Oral Pathol Oral Radiol Endod 2011, 111, 71-77.

[75] Giroldo LM, Felipe MP, de Oliveira MA, Munin E, Alves PL, Costa MS: Photodynamic antimicrobial chemotherapy (PACT) with methylene blue increases membrane permeability in Candida albicans. Lasers Med Sci 2009, 24, 109-112.

[76] Mima EG, Pavarina AC, Silva MM, Ribeiro DG, Vergani CE, Kurachi C, Bagnato VS: Denture stomatitis treated with photodynamic therapy: Five cases. Oral Surg Oral Med Oral Pathol Oral Radiol Endod 2011, 112, 602-608.

[77] Mima EG, Vergani CE, Machado AL, Massucato EMS, Colombo AL, Bagnato VS, Pavarina AC: Comparison of Photodynamic Therapy versus conventional antifungal therapy for the treatment of denture stomatitis: A randomized clinical trial. Clin Microbiol Infect 2012, 18, 380-388.

\section{Address for correspondence:}

Ewa Prażmo

Department of Conservative Dentistry and Endodontics

Medical University of Warsaw

ul. Miodowa 18

00-246 Warszawa

Poland

Tel.: +48668348564

E-mail: ewagg@interia.eu

Conflict of interest: None declared

Received: 12.08 .2014

Revised: 2.10 .2014

Accepted: 5.11.2014 